\title{
artigo
}

\section{Participação popular, controle social e organização em conselhos de saúde: revisão integrativa}

\author{
Popular participation, social control and organization in health councils: an integrative review
}

Participación popular, control social y organización en los consejos de salud: revisión integradora

\begin{abstract}
RESUMO
Objetivo: objetiva-se analisar as produções científicas que descrevem a forma como os Conselhos Gestores de Saúde promovem a Participação Popular. Método: trata-se de uma revisão integrativa de literatura com abordagem qualitativa, baseada nas etapas de Ganong. Resultados: foram identificados 25 artigos, publicados nos últimos sete anos em bases de dados nacionais e internacionais. Através do agrupamento dos dados foi possível a construção de categorias relacionadas às práticas dos Conselhos Gestores: Participação Popular; Controle Social e Funcionamento e Organização dos Conselhos. São perceptíveis nos estudos analisados as dificuldades relativas à Participação Popular em Conselhos de uma maneira geral, em função de demandas políticas e da falta de conhecimento por parte dos atores envolvidos acerca da importância de sua atuação para favorecer mudanças efetivas nos espaços públicos. Conclusão: conclui-se que a compreensão destes processos podem oferecer subsídios para o fomento da Participação Popular nos Conselhos Gestores e possibilitar a oferta de novas diretrizes para a construção de um novo perfil cidadão.
\end{abstract}

DESCRITORES: Participação comunitária; Conselhos de saúde; Políticas públicas de saúde; Organização social.

\section{ABSTRACT}

Objective: This study analyzes the scientific productions that describe how the Health Councils Managers promote Popular Participation. Method: Was used the method of integrative review with qualitative approach, based on the steps of Ganong. Results: We identified 25 articles published in the last seven years in national and international databases. By pooling data it was possible the construction of categories related to the practices of management councils: Popular Participation; Social Control and Operation and Organisation of Councils. Interpretations: They are noticeable in the studies analyzed the difficulties relating to the Popular Participation in Councils in general, due to political demands and the lack of knowledge among stakeholders on the importance of its work to promote effective changes in public spaces. Conclusions: Understanding these processes may offer subsidies for the promotion of Popular Participation in Management Councils and enable the provision of new guidelines for the construction of a new profile citizen.

DESCRIPTORS: Consumer participation; Health councils; Public health policy; Social organization.

\section{RESUMEN}

Objetivo: Este estudio analiza las producciones científicas que describen cómo los Consejos de Gestión de Salud promueven la participación popular. Método: Se utilizó el método de revisión integradora de la literatura con un enfoque cualitativo, basado en las etapas de Ganong. Resultados: fueron identificados 25 artículos publicados en los últimos siete años en las bases de datos nacionales e internacionales. Mediante la combinación de los datos fue posible la construcción de categorías relacionadas con las prácticas de los Consejos de Gestión: La participación popular; El control social y de funcionamiento y organización de los Consejos. Interpretaciones: Es perceptible en los estudios analizados dificultades relativas a la participación popular en los Consejos en general, debido a las demandas políticas y la falta de conocimiento por parte de los actores involucrados sobre la importancia de sus actividades para promover cambios efectivos en los espacios públicos. Conclusiones: La comprensión de estos procesos puede ofrecer subsidios para la promoción de la participación popular en los consejos de gestión y permitir la provisión de nuevas directrices para la construcción de un nuevo perfil de ciudadano.

DESCRIPTORES: Participación comunitaria; Consejos de salud; Políticas públicas de salud; Organización social.

RECEBIDO EM: 07/12/2020 APROVADO EM: 19/01/2021 


\section{Juliano de Amorim Busana}

Enfermeiro. Doutorando do Programa de Pós-Graduação em Enfermagem da Universidade Federal de Santa Catarina - PEN/ UFSC. Professor do Departamento de Enfermagem do Centro Universátário Avantis - UNIAVAN. Florianópolis (SC).

ORCID: 0000-0001-7004-2917

\section{Ivonete Terezinha Schülter Buss Heidemann}

Enfermeira. Doutora em Enfermagem em Saúde Pública pela Universidade São Paulo (USP), Professora do Departamento de Enfermagem e do PEN/UFSC. Florianópolis (SC).

ORCID: 0000-0002-0058-5120

\section{Rosane Gonçalves Nitschke}

Enfermeira. Doutora em Filosofia de Enfermagem pela UFSC/SORBONNE/Paris V. Professora do Departamento de Enfermagem e do PEN/UFSC. Florianópolis (SC).

ORCID: 0000-0002-1963-907X

\section{Adriana Dutra Tholl}

Enfermeira. Doutora em Filosofia de Enfermagem pela UFSC. Professora do Departamento de Enfermagem e do Programa de Pós-Graduação Gestão do Cuidado da Universidade Federal de Santa Catarina - PEN/UFSC. Florianópolis (SC).

ORCID: 0000-0002-5084-9972

\section{Michelle Kuntz Durand}

Enfermeira. Doutora em Filosofia de Enfermagem pela UFSC. Professora do Departamento de Enfermagem da Universidade Federal de Santa Catarina. Florianópolis (SC).

ORCID: 0000-0003-3660-6859

\section{Robriane Prosdocimi Menegat}

Enfermeira. Doutoranda do Programa de Pós-Graduação em Enfermagem da Universidade Federal de Santa Catarina - PEN/ UFSC. Enfermeira Assistencial no Hospital Universitário de Santa Maria - HUSM. Santa Maria (RS).

ORCID: 0000-0003-3550-7816

\section{INTRODUÇÃO}

0 s Conselhos Gestores constituem-se uma das principais experiências democráticas contemporâneas no Brasil, foram criados para viabilizar a gestão descentralizada e participativa de políticas públicas, tornando-se meios públicos de deliberação e estão presentes em boa parte dos municípios brasileiros, promovendo discussões acerca de inúmeros temas, tais como saúde, moradia, transporte e educação. Tais conselhos adquiriram caráter de instituição e o fortalecimento do diálogo entre o governo e a sociedade tem a intenção de assegurar uma distribuição justa e eficiente dos recursos públicos ${ }^{(1)}$.

A participação popular nos conselhos gestores de saúde é prevista pela Constituição Federal de 1988, em seu artigo 198, que comporta as diretrizes do Sistema Único de Saúde: descentralização, integralidade e participação da comunidade ${ }^{(2)}$.

A regulamentação deste novo modelo participativo ocorreu no final do ano de 1990 com as Leis 8.080 e 8.142. Esta última legisla sobre a participação social institucionalizada, através de Conferências e Conselhos de Saúde em todas as suas instâncias (Federal, Estadual e Municipal), que passaram a ser um dos pilares do SUS. Os Conselhos de Saúde tem a função de deliberar e tomar decisões, formular estratégias, controlar e fiscalizar a execução das políticas de saúde ${ }^{(3-4)}$. Porém, estas funções não tem se dado de maneira efetiva, pois há estudos ${ }^{(5-7)}$ detectando problemas na qualidade da participação e estruturação dos conselhos, bem como sua compreensão enquanto esfera pública de exercício da cidadania.

A estruturação dos conselhos municipais ainda é fato recente na história do país e por isto, constitui campo profícuo de pesquisas, incluindo seus movimentos internos de funcionamento e o estímulo à participação social efetiva, seu papel e grau de decisão. Para tanto, depreende-se que participar é um processo de conquista que presume não apenas compromisso, mas também envolvimento, exigindo do cidadão iniciativa e interesse pelas políticas e serviços públicos dos quais este é beneficiário ${ }^{(8)}$.

Mesmo diante da lei que regularizou os Conselhos Gestores já em 1988, somente em 1996, legislação que está em vigor hoje no Brasil, preconiza-se que, para o recebimento de recursos destinados às áreas sociais, os municípios devem criar Conselhos Gestores. Isso, explica as razões para que parte dos Conselhos Municipais tenha se efetivado apenas após essa data. Neste contexto, para que os representantes tenham condições de serem os defensores do segmento que representam é necessário que os Conselhos sejam paritários não somente em número, mas também no exercício da participaçãoo ${ }^{(9)}$.

Estudo $^{(1)}$ revelou que os conselhos em geral ainda são pouco conhecidos para além do universo da sociedade civil diretamente envolvida e, por conseguinte, apresentam inúmeras fragilidades no que compete aos mecanismos legais sobre as 
decisões tomadas em seu interior. É igualmente possível afirmar que há frágil conexão entre os conselhos e os movimentos populares, demonstrando talvez, uma descontinuidade entre a mobilização popular e a atuação nestas instâncias ${ }^{(10)}$.

Para tanto, é fundamental que haja participação da maioria dos segmentos da sociedade no processo de tomada de decisões através de debate público, consulta, pressão popular ou discussões em diferentes esferas, propondo alternativas que viabilizem decisões que venham favorecer a comunidade como um todo. Os indivíduos devem conscientizar-se da importância de sua participação, elegendo e controlando os representantes, não com o intuito de substituir o Estado, mas favorecendo a melhora da qualidade das decisões e ao mesmo tempo, exigindo a responsabilização dos gestores, pois desta forma será possível compatibilizar a participação de todos os atores envolvidos ${ }^{(11)}$.

Para tanto, questiona-se: Quais são as características da produção científica sobre participação popular por meio das práticas dos Conselhos Gestores de Saúde? Desta forma, o objetivo desta revisão integrativa consiste em: Caracterizar a produção científica sobre participação popular, controle social e organização em conselhos gestores de saúde.

\section{MÉTODO}

A revisão integrativa é um método de pesquisa que busca, avalia e sintetiza criticamente estudos realizados, revelando sua produção e identificando possíveis lacunas. Constitui-se, então, em uma ferramenta ímpar para pesquisas aplicadas à saúde, tanto pela possibilidade de sintetizar resultados acerca da temática investigada, como pela produção do novo conhecimento ${ }^{(12)}$.

Assim sendo, esta investigação teve seu início após consultas à plataforma virtual Biblioteca Virtual em Saúde (BVS) e a Bases de Dados da Enfermagem (BDENF), com a utilização das seguintes descritores em português, inglês e espanhol (Quadro 1).

Para a pesquisa, utilizou-se a BVS pois é composta por várias bases de dados indexadas a ela, sendo estas atualizadas com regularidade por uma Rede de Colaboração. Algumas das bases de dados vinculadas a BVS são: LILACS, MEDLINE, MEDCARIB, PAHO-IRIS, WHOLIS.

Destacamos a LILACS (Literatura Latino-americana e do Caribe em Ciências da Saúde) como a base de dados com mais artigos referentes ao tema desta pesquisa.

Para a realização deste estudo, optou-se pela revisão integrativa da literatura fundamentada nos estudos de Ganong ${ }^{(13)}$, constituída por seis etapas: identificação do problema ou questionamento, estabelecimento de critérios de inclusão/ exclusão de artigos (seleção da amostra), definição das informações a serem extraídas dos artigos selecionados, análise das informações, interpretação dos resultados e apresentação da revisão.

\begin{tabular}{|c|c|c|c|}
\hline \multirow{3}{*}{$\begin{array}{l}\text { PLATAFORMA } \\
\text { VIRTUAL } \\
\text { E BASE DE } \\
\text { DADOS }\end{array}$} & \multicolumn{3}{|c|}{ DESCRITORES } \\
\hline & \multicolumn{3}{|c|}{$\begin{array}{l}\text { "Conselhos de Saúde" and "Enfermagem" } \\
\text { "Conselhos de Saúde" and "Participação Comunitária" } \\
\text { "Enfermagem" and "Participação Comunitária" } \\
\text { "Conselhos de Saúde" and "Enfermagem" and "Participação Comunitária" }\end{array}$} \\
\hline & Encontrados & Selecionados & Excluídas \\
\hline BVS & 2.125 & 22 & 2.103 \\
\hline \multirow[t]{4}{*}{ BDENF } & 121 & 03 & 118 \\
\hline & \multicolumn{3}{|c|}{ Total encontrado: 2.246} \\
\hline & \multicolumn{3}{|c|}{ Total excluído: 2.221} \\
\hline & \multicolumn{3}{|c|}{ Total selecionado: 25} \\
\hline
\end{tabular}

Para guiar a presente revisão, formulou-se a seguinte questão norteadora: quais são as evidências científicas de promoção ou compreensão dos processos referentes à participação popular através das práticas dos Conselhos Gestores de Saúde, contidas na literatura no período de 2007 a 2013? Os critérios para inclusão das publicações neste estudo de revisão integrativa foram: artigos disponíveis eletronicamente na íntegra, sobre o tema proposto; artigos publicados em português, espanhol e inglês, no período de janeiro de 2007 a dezembro de 2013, referentes à participação popular e conselhos gestores. Excluíram-se deste estudo editoriais, cartas, artigos de opinião, comentários, ensaios e notas prévias bem como as publicações duplicadas em mais de uma base de dados, teses, dissertações e manuais.

A análise e síntese dos dados foram realizadas após tradução e leitura exaustiva dos artigos, por intermédio das seguintes etapas: 1) identificação da hipótese ou questão norteadora -elaboração de uma problemática pelo pesquisador de maneira clara e objetiva, seguida da busca pelos descritores ou palavras-chaves; 2) seleção da amostragem - determinação dos critérios de inclusão ou exclusão, momento de estabelecer a transparência para que proporcione profundidade, qualidade e confiabilidade na seleção; 3) categorização dos estudos - definição quanto à extração das informações dos artigos revisados com o objetivo de sumarizar e organizar tais informações; 4) avaliação dos estudos - análise crítica dos dados extraídos; 5) discussão e interpretação dos resultados - comparação e fundamentação dos principais resultados com o conhecimento teórico e avaliação quanto sua aplicabilidade; 6) apresentação da revisão integrativa e síntese do conhecimento - informações de cada artigo revisado de maneira sucinta e sistematizadas demonstrando as evidências encontradas ${ }^{(13)}$.

Os dados foram coletados entre os meses de março a abril de 2014. Os dados extraídos foram transcritos para o instrumento proposto possibilitando o detalhamento de cada estudo, sendo organizados 
por planilhas em ordem numérica crescente, no programa Microsoft Excel 2007, de acordo com: ano de publicação, título, autores, formação profissional dos autores, base dedados, tipo/abordagem do estudo e principais aspectos ou resultados.

Para a avaliação dos estudos incluídos nesta revisão, levaram-se em consideração suas semelhanças, tendo como intenção organizar e sumarizar as informações de ma- neira concisa, analisar questões que podem ser utilizadas na avaliação crítica dos estudos selecionados, como: questão de pesquisa, a base para a questão da pesquisa, estruturação e relevância da questão de pesquisas, metodologia do estudo e a adequação dos sujeitos à questão da pesquisa ${ }^{(14)}$. Quanto aos aspectos éticos, foram respeitados os direitos autorais e o conteúdo, não havendo modificação destes em benefício da revisão.

\section{RESULTADOS}

O Quadro 01 permite a leitura comparativa entre as informaçóes recolhidas em cada uma das fontes, que foram consideradas pertinentes e incluídas no estudo, apresentadas por ordem cronológica.

A amostra desta revisão constitui-se de 25 artigos (Quadro 01) dos quais 08 (32\%), foram publicados em periódicos pertencen-

\section{QUADRO 01: Apresentação dos artigos selecionados, autores, títulos, periódicos, bases de dados e ano das publicações, 2014.}

\begin{tabular}{|c|c|c|c|c|}
\hline & AUTORES & TÍTULO & NE & BASE \\
\hline 1 & Pestana, Vargas, Cunha (2007). & $\begin{array}{l}\text { Contradições surgidas no Conselho Gestor da Unidade Básica de } \\
\text { Saúde da Familia de Vargem Grande, Município de Teresópolis-RJ. }\end{array}$ & 4 & LILACS \\
\hline 2 & Arantes, Mesquita, Machado, Ogata (2007). & $\begin{array}{l}\text { O controle social no Sistema Único de Saúde: concepções e } \\
\text { ações de enfermeiras da atenção básica }\end{array}$ & 4 & LILACS \\
\hline 3 & Kleba, Comerlatto, Colliselli (2007). & $\begin{array}{l}\text { Promoção do empoderamento com conselhos gestores de um polo } \\
\text { de educação permanente em saúde }\end{array}$ & 4 & LILACS \\
\hline 4 & $\begin{array}{l}\text { Martins, Cotta, Mendes, Franceschinni, Priore, } \\
\text { Dias, Siqueira-Batista (2008). }\end{array}$ & $\begin{array}{l}\text { Conselhos de saúde e a participação social no Brasil: matizes da } \\
\text { utopia }\end{array}$ & 4 & LILACS \\
\hline 5 & Bispo Júnior, Sampaio (2008). & Participação social em saúde em áreas rurais do Nordeste do Brasil & 4 & LILACS \\
\hline 6 & Bezerra, Araújo (2009). & $\begin{array}{l}\text { Conselho Municipal de Saúde de Pedras do Fogo - PB: um estudo } \\
\text { sobre participação }\end{array}$ & 4 & LILACS \\
\hline 7 & Arantes, Mesquita, Machado, Ogata (2009). & $\begin{array}{l}\text { Controle social na saúde: discutindo os resultados de uma pesquisa } \\
\text { com enfermeiras }\end{array}$ & 4 & LILACS \\
\hline 8 & $\begin{array}{c}\text { Machado, Farah, Barros, Taborda, Assis, Valle, } \\
\text { Faria (2009). }\end{array}$ & $\begin{array}{l}\text { Interação universidade e comunidade através dos movimentos } \\
\text { sociais dos bairros Santa Luzia e Ipiranga de Juiz de Fora-MG }\end{array}$ & 4 & LILACS \\
\hline 9 & Oliveira, Conciani (2009). & Participação social e reforma psiquiátrica: um estudo de caso & 4 & LILACS \\
\hline 10 & Cotta, Cazal, Rodrigues (2009). & $\begin{array}{l}\text { Participação, controle social e exercício da cidadania: a (des)infor- } \\
\text { mação como obstáculo à atuação dos conselheiros de saúde }\end{array}$ & 4 & LILACS \\
\hline 11 & Matuoka, Ogata (2010). & $\begin{array}{l}\text { Análise qualitativa dos conselhos locais da atenção básica de São } \\
\text { Carlos: a dinâmica de funcionamento e participação }\end{array}$ & 4 & LILACS \\
\hline 12 & $\begin{array}{l}\text { Morgan, Martins, Fernandes, Pereira, Bastos } \\
\text { (2010). }\end{array}$ & $\begin{array}{l}\text { Conselhos de saúde: perfil dos usuários e das entidades por eles } \\
\text { representadas }\end{array}$ & 4 & $\begin{array}{l}\text { BDE- } \\
\text { NF }\end{array}$ \\
\hline 13 & $\begin{array}{l}\text { Kleba, Matiello, Comerlatto, Renk, Colliselli } \\
\text { (2010). }\end{array}$ & $\begin{array}{l}\text { O papel dos conselhos gestores de políticas públicas: um debate a } \\
\text { partir das práticas em Conselhos Municipais de Chapecó (SC) }\end{array}$ & 4 & LILACS \\
\hline 14 & $\begin{array}{l}\text { Budó, Oliveira, Garcia, Simon, Schmith, Mat- } \\
\text { tioni (2010). }\end{array}$ & $\begin{array}{l}\text { Redes sociais e participação em uma comunidade referenciada a } \\
\text { uma unidade de saúde da família }\end{array}$ & 4 & $\begin{array}{l}\text { BDE- } \\
\text { NF }\end{array}$ \\
\hline 15 & Landerhal, Unfer, Braun, Skupien (2010). & $\begin{array}{l}\text { Resoluções do Conselho de Saúde: instrumento de controle social } \\
\text { ou documento burocrático? }\end{array}$ & 4 & LILACS \\
\hline 16 & Silva, Drehmer, Langlois (2010). & $\begin{array}{c}\text { Percepção de líderes de uma comunidade de Porto Alegre/RS em } \\
\text { relação ao Programa Saúde da Familia }\end{array}$ & 4 & LILACS \\
\hline 17 & Vieira, Calvo (2011). & $\begin{array}{l}\text { Avaliação das condições de atuação de Conselhos Municipais de } \\
\text { Saúde no Estado de Santa Catarina, Brasil }\end{array}$ & 4 & LILACS \\
\hline 18 & Zambon, Ogata (2011). & $\begin{array}{l}\text { Configurações dos Conselhos Municipais de Saúde de uma região } \\
\text { no Estado de São Paulo }\end{array}$ & 4 & LILACS \\
\hline 19 & Batagello, Benevides, Portillo (2011). & Conselhos de saúde: controle social e moralidade & 4 & LILACS \\
\hline
\end{tabular}




\begin{tabular}{|c|c|c|c|c|}
\hline 20 & Ribeiro, Nascimento (2011). & $\begin{array}{l}\text { Exercício de cidadania nos conselhos locais de saúde: a(re)significa- } \\
\text { ção do ser sujeito }\end{array}$ & 4 & LILACS \\
\hline 21 & $\begin{array}{c}\text { Cotta, Martins, Batista, Franceschinni, Priore, } \\
\text { Mendes (2011). }\end{array}$ & $\begin{array}{l}\text { O controle social em cena: refletindo sobre a participação popular } \\
\text { no contexto dos Conselhos de Saúde }\end{array}$ & 4 & LILACS \\
\hline 22 & $\begin{array}{l}\text { Santos, Sousa, Gurgel, Bezerra, Barros } \\
\text { (2011). }\end{array}$ & $\begin{array}{l}\text { Política de práticas integrativas em Recife: análise da participação } \\
\text { dos atores }\end{array}$ & 4 & LILACS \\
\hline 23 & Azevedo, Lucena, Holanda (2012). & $\begin{array}{l}\text { O controle social enquanto instrumento para a qualidade da assis- } \\
\text { tência na estratégia de saúde da familia }\end{array}$ & 4 & $\begin{array}{l}\text { BDE- } \\
\text { NF }\end{array}$ \\
\hline 24 & Zambon, Ogata (2013). & $\begin{array}{l}\text { Controle social do Sistema Único de Saúde: o que pensam os con- } \\
\text { selheiros municipais de saúde }\end{array}$ & 4 & LILACS \\
\hline 25 & $\begin{array}{l}\text { Cardoso, Cezar-Vaz, Costa, Bonow, Almeida } \\
\text { (2013). }\end{array}$ & $\begin{array}{l}\text { Promoção da saúde e participação comunitária em grupos locais } \\
\text { organizados }\end{array}$ & 4 & LILACS \\
\hline
\end{tabular}

tes à área da Enfermagem, 16 (64\%), foram publicados na área da saúde em geral e 1 (4\%), na área da Odontologia. Todos os estudos identificados foram classificados com nível de evidência 4, baseados na categorização da Agency for Helthcare Research and Quality (AHQR).

O Estado que mais predominou em número de periódicos e consequentemente em número de artigos foi o Estado do Rio de Janeiro (RJ), apresentando respectivamente 05 periódicos $(29,4 \%)$ e 11 artigos (44\%); seguido de São Paulo (SP), com 05 periódicos (29,4\%) e 05 artigos (20\%); Rio Grande do Sul (RS), com 02 periódicos $(11,8 \%)$ e 02 artigos (8\%); Santa Catarina (SC), com 01 periódico (5,9\%) e 02 artigos (8\%); Distrito Federal (DF), com 01 periódico (5,9\%) e 02 artigos (8\%); Minas Gerais (MG), Bahia (BA) e Estados Unidos da América (EUA), cada um com 01 periódico $(5,9 \%)$ e 01 artigo (4\%). Vale ressaltar neste caso a presença de um artigo publicado em um periódico Norte Americano, sobre esta temática, sendo este a Revista Panamericana de Salud Pública/Pan American Journal of Public Health (RPSP/PAJPH), que é a principal publicação de caráter técnico-científico da Organização Pan-Americana da Saúde (OPAS/OMS).

Em relação as bases de dados, apenas duas apresentaram artigos, sendo a LILACS com 22 representando (88\%), das publicações encontradas e a BDENF com 03 totalizando apenas (12\%).

Quanto aos países de publicação, 24 artigos (96\%), foram publicados em periódi- cos nacionais e apenas 01 (4\%), em periódico norte-americano.

Dos 25 artigos, 03 (12\%) foram publicados em 2007; 02 (8\%) em 2008; 05 (20\%) em 2009; 06 (24\%) em 2010; 06 (24\%) em 2011; 01 (4\%) em 2012 e 02 (8\%) em 2013.

No que compete aos autores, verificou-se a presença de 73 autores distintos nos 25 artigos elencados para este estudo. Destes aparecem profissionais das áreas de Enfermagem 32 (43,8\%); Odontologia 10 (13,7\%); Nutrição 8 (11\%); Medicina 05 (6,8\%); Assistência Social 03 (4,1\%); Fisioterapia, Administração de Empresas, Acadêmico de Medicina, Acadêmico de Enfermagem, cada um com 02 profissionais (2,7\%); Terapia Ocupacional, Filosofia, História, Arquitetura e Urbanismo, Ciências Biológicas, Ciências Sociais, cada um com 01 profissional $(1,4 \%)$; e por fim $01(1,4 \%)$ não identificado.

Com relação à titulação, dos 73 autores, 32 (43,8\%), são doutores; 19 (26\%), são mestres; 04 (5,5\%), são especialistas; 13 (17,8\%), são graduados; 04 (5,5\%), são acadêmicos nas diversas áreas citadas acima e $01(1,4 \%)$ autor não informou sua titulação.

Como forma de organizar o vasto conteúdo apresentado nos artigos incluídos no estudo, recorreu-se a sua organização por meio de análise crítica e qualitativa, sistematizando-se esse conteúdo nos temas que emergiram de sua leitura integrada e que são apresentados, a seguir.

\section{Tema 1 - Participação nos conselhos gestores}

A participação popular nos Conselhos Municipais de Saúde tem gerado questionamentos acerca de seu funcionamento, bem como preocupações sobre a dinâmica desta participação ${ }^{(15)}$.

De acordo com um dos estudos utilizados para esta revisão ${ }^{(16)}$, os conselheiros usuários são, em sua maioria, do sexo masculino, têm idade entre 31 a 72 anos e formação de nível superior completo ou incompleto. Entre as entidades representadas pelos usuários, destacam-se as associações de moradores, portadores de deficiências e portadores de patologias. Identifica-se que as entidades de maior expressividade são aquelas compostas por pessoas portadoras de alguma patologia ou deficiência, que, por objetivos em comum, se unem em busca de ganhos cíveis que amenizem o fato de "serem" ou "estarem" doentes. Existe uma grande heterogeneidade de sujeitos na construção desse processo, com peculiaridades que envolvem desde questões ideológicas, socioeconômicas e políticas até questões como consciência sanitária, exercício de cidadania, participação social em trabalhos comunitários, reconhecimento sobre os seus direitos e deveres enquanto cidadãos, dentre outras, que podem interferir de forma eficiente na concretização das mudanças sociais ${ }^{(17-18)}$.

O reconhecimento da necessidade de potencializar e efetivar a cidadania, fortalecendo a gestão participativa está presente em parte dos estudos que compóe essa revisão ${ }^{(15,19,20)}$. As preocupações advindas 
da participação popular são da ordem da autonomia dos sujeitos nas discussões e organização das formas de participação popular, que não se dão de forma processual, fazendo com que o processo não seja reconhecido como deliberativo, mas sim, burocrático, fiscalizatório e pouco propositivo, denotando um desempenho ruim por parte dos conselhos. Como fatores negativos, há sabidamente conflitos gerados por eleições políticas e por desvios de responsabilidade por parte do poder executivo ${ }^{(15,21)} \mathrm{e}$, em alguns espaços, desconhecimentos das normas que legitimam a atuação dos conselhos, imputando responsabilidades sobre o desconhecimento de alguns representantes sobre a importância da participaçãoo ${ }^{(21,18)}$.

Neste sentido, a representatividade é, por vezes, observada como uma situação problemática em todas as esferas e identificam-se usuários, trabalhadores e gestores como pouco participativos ou mesmo pouco capacitados política e tecnicamente, tornando os conselhos ineficientes ${ }^{(15,22,23,24)}$. Outras fragilidades tais como desconhecimento das normas que legitimam a atuação do conselho ou da própria condição de representante e da importância da participação de base para o fortalecimento de sua participação contribui para a inércia dos representados ${ }^{(21,17,23,24)}$, gerando discussões sobre a necessidade de empoderamento e libertação dos sujeitos a fim de minimizar processos de exclusão e marginalização da população, reforçando a construção da cidadania no país, fortalecendo inclusive, o próprio conceito de cidadania ${ }^{(25,26,27)}$.

Neste sentido, é questionável a compreensão dos processos de participação popular, pois eles não podem constituir-se apenas como uma forma de suprir uma exigência legal, não garantindo o direito de inclusão do cidadão no processo decisório em saúde ${ }^{(23)}$. Em algumas instâncias, são apresentadas irregularidades quanto à composição e à posse de conselheiros, a alta rotatividade de representantes e as constantes "reformulações" da composição do conselho, bem como, observações quanto às irregularidades de frequência/comparecimento nas reunióes ${ }^{(26)}$.

Os participantes mostram-se insatisfei- tos com as práticas dos Conselhos Municipais de Saúde e apontam descrenças quanto à representatividade e ao poder desses conselhos. Há apontamentos igualmente importantes sobre a pouca participação dos sujeitos nas atividades grupais, nos colegiados e movimentos de exercício de cidadania, sendo esse papel desempenhado por poucos, pois os processos de trabalho das equipes não facilitam ou promovem a participação. Todavia, ressalta-se que quando há participação, os resultados são evidentes e positivos, favorecendo a consolidação de ações amplas e efetivass ${ }^{(28)}$. É preciso repensar as estratégias de participação social no Brasil a partir da perspectiva do desenvolvimento de práticas sociais de amadurecimento político e elevação da consciência cidadã ${ }^{(26)}$.

\section{Tema 2: Controle Social}

Estudos sobre os conselhos de saúde (29,31) $^{(2)}$ indicam uma significativa dificuldade na efetiva participação da população, apontando para a necessidade da construção de novos significados para esses espaços formais de participação social. A participação política e o controle social não podem depender apenas formulações legais, uma vez que eles somente se materializarão no conjunto das práticas sociais que constituem e atravessam o sistema de saúde. Daí a necessária compreensão de que os conselhos de saúde não substituem os movimentos sociais $\mathrm{e}$ que são esses movimentos que devem nortear as ações dos conselhos.

Inúmeras possibilidades de atuação são apontadas, mostrando os diferentes atores responsáveis pela sua execuçãa ${ }^{(31)}$. O controle social é concebido como uma ferramenta que garante direitos à saúde, representando um conjunto de ações básicas que resultam no bem estar da população. A integração entre vários atores sociais parece indispensável no contexto de uma dimensão ética, com defesa do direito igualitário à saúde e fortalecimento do controle social. Como resposta ao desafio de efetivação do controle social em saúde na realidade pesquisada, a integração entre vários atores sociais parece se mostrar indispensável para que se contextualize uma dimensão ética, com defesa do direito igualitário à saúde e fortalecimento do controle social ${ }^{(32)}$.

Informações revelam sobrecarga de atribuições burocráticas ${ }^{(33)}$, restringindo o debate político inerente ao papel dos conselheiros. Além disso, questionamos a legitimidade de suas atribuições, considerando as condições objetivas de sua participação: o caráter voluntário, não profissional, não remunerado; o tempo restrito dos encontros; a falta de estrutura física e operacional qualificada e autônoma, entre outras. Os conselhos gestores são espaços de exercício de cidadania, o que requer maior atuação na criação e no fortalecimento de canais e processos de diálogo com diferentes atores sociais, constituindo elos na rede de parcerias em prol do enfrentamento dos problemas sociais da cidade e da construção de condições favoráveis à vida.

Os conselhos de saúde e conferências são apontados como meios legítimos e privilegiados de controle social. Enquanto as instâncias formais de participação do SUS encontram-se esvaziadas do estabelecimento de diretrizes e do controle da execução de algumas políticas, outros espaços, informais e "marginais" aos instituídos, se constroem nos contextos dos municípios ${ }^{(34)}$. O mero funcionamento regular dos conselhos não garante que exista efetivo controle social( ${ }^{(26)}$. Sugestiona-se que as práticas burocratizadas, com a predominância de aprovações de programas ou projetos predominantemente ligados à prestação de serviços assistenciais, sem que se vislumbrem proposições políticas de saúde pelo setor, influenciam na forma como as resoluções vêm sendo formalizadas e descaracterizam a efetividade de suas ações e a invisibilidade destas para a população em geral ${ }^{(26)}$.

\section{Tema 3: Funcionamento e Organiza- ção dos conselhos gestores em saúde}

Um estudo ${ }^{(22)}$ demonstrou a existência de preocupações acerca da eleição para presidente dos conselhos e a integridade e transparência deste processo, além de garantias de que os mandatos não sejam coincidentes com o executivo, estruturas administrativas e comissões. Mostra, neste sentido, a existência de legislações inconsis- 
tentes quanto às normas locais e nacionais em relação ao caráter deliberativo, paridade dos usuários, regimento interno, gestor como presidente nato e não garantia de estrutura administrativa e financeira para funcionamento, reforçando a fragilidade do entendimento sobre os conselhos para a população em geral.

Parte dos problemas apontados na organização e funcionamento dos conselhos gestores geram impasses e problemas que são de ordem política, econômica, social e cultural que transcendem a resolução pelo conselho gestor. Percebe-se que as atribuições previstas para um conselho gestor revelam uma prática de controle restrita à racionalização do serviço através do gerenciamento administrativo da unidade, fazendo com que o conselho gestor não consiga, de fato, interferir na política de saúde e na destinação das verbas públicas. Aponta-se também a necessidade de ampliar as ações assistencialistas, os cursos profissionalizantes oferecidos e as atividades culturais ${ }^{(35)}$. De maneira geral, os conselhos, em suas fragilidades e potencialidades, possuem boa inserção na comunidade e recebem apoio de instituições religiosas e educacionais ${ }^{(36)}$.

Outras demandas destacadas são as que relatam algumas dificuldades que prejudicam o funcionamento efetivo dos conselhos, tais como a falta de preparo dos profissionais e dos usuários para atuarem e os baixos resultados alcançados pelos conselhos junto ao gestor municipal. A educação na saúde deva estar inserida em uma política de educação permanente que vise à formação dos diferentes segmentos: usuários, trabalhadores e gestores para a participação social no SUS. O envolvimento com a educação permanente deve ocorrer por parte de vários atores, como: as universidades e instituições com cursos na área da saúde; os hospitais de ensino; os estudantes da área da saúde; os trabalhadores de saúde; os conselhos de saúde; entre outros ${ }^{(37)}$.

Para garantir que os Conselhos de Saúde exerçam de forma adequada seu papel, é necessário buscar aprimoramento dos dispositivos legais e também enfatizar o aprimoramento do tema participação social em todas as esferas de formação de trabalhadores em saúde e participação(22).

\section{DISCUSSÃO}

$\mathrm{Na}$ presente revisão, percebeu-se o envolvimento das mais diversas áreas de atuação e inúmeros profissionais envolvidos com a disseminação e compreensão, com estudos sobre o tema. $\mathrm{Na}$ autoria dos artigos, profissionais Enfermeiros, Nutricionistas, Médicos, Odontólogos, Assistentes Sociais, Fisioterapeutas, Administradores de Empresas, Acadêmicos de Medicina, Acadêmicos de Enfermagem, Terapeuta Ocupacional, Filósofo, Historiador, Arquiteto e Urbanista, Cientista Biológico, Cientista Social se propuseram a contribuir com o tema e divulgar estudos e amplos processos reflexivos sobre a importância da participação popular e/ou dos conselhos gestores em saúde, destacando-se assim, sua relevância, nas diversas áreas profissionais.

No Brasil, devido aos momentos políticos vividos nos últimos anos, cercado de escândalos e manifestações civis, há tendência crescente de interesse por parte da população, bem como é manifesto o desejo de ser mais atuante, de participarem do desenvolvimento político democrático da nação, trazendo à tona a intencionalidade do cidadão em praticar a cidadania e assim "fazer a diferença".

A incipiente participação popular e o controle social nos conselhos gestores de saúde tem sido demonstrada em estudos ${ }^{(38)}$, devido aos limites e dificuldades apontadas pelos autores, tais como: reuniões deliberativas, mas sem implementação efetiva destas deliberações; paridade no conselho apenas quantitativa e formal; pouca qualificação dos conselheiros para o exercício de suas funções, fator este que se constitui num impeditivo de intervenções mais crítica e mais ativas do conselho; a função da fiscalização é frágil - os conselheiros exercitam, prioritariamente, o papel de receber denúncias e provocar discussões; existe apatia por parte de muitos conselheiros ou mesmo desmotivação para o exercício de suas funções; há desconhecimento dos gestores e servidores da unidade sobre o papel do conselho local; existe pouca articulação do conselho municipal e poder público municipal com os conselhos locais de saúde.

Uma vez que, a falta de conhecimento a respeito do real papel do conselho e dos conselheiros, o controle social surge nos estudos como um fator de comprometimento da qualidade de atuação dos conselhos, pois, para ser representativo o conselho necessita ter a capacidade de prover informações, contestar, compartilhar poder, além de servir como informante para o Estado, necessita utilizar seu poder para atuar representando a populaçã̃o ${ }^{(39)}$. Devido, a efetividade do controle social dos conselhos estar diretamente ligada à paridade, representatividade e pressão social para que a deliberação se concretize ${ }^{(40)}$.

Nos estudos analisados, contatou-se também que o processo decisório é frágil devido ao desconhecimento dos conselheiros e da população a respeito do verdadeiro papel do conselho e dos conselheiros em si. Fazendo assim, com que, os indivíduos não participem dos processos de discussão e das decisões dos conselhos do qual participam. Quanto maior for o acúmulo de capital social, maiores serão as possibilidades de que um cidadão comum possa participar efetivamente deste momento $^{(41)}$. Assim, no processo de análise para posterior deliberação, os indivíduos necessitam ter conhecimento sobre a natureza política da questão para que possam deliberar, junto com outros atores que talvez possuam um capital cultural e econômico mais elevado, com mais propriedade.

A capacitação constante dos conselheiros para que o mesmo tenha maior efetividade e fomente a participação popular nos conselhos, pode ser uma forma de diminuir a rotatividade e baixa aderência dos usuários nos conselhos. Os conselhos apresentaram irregularidades em relação à sua composição e à posse dos conselheiros, destacando a constante quebra da paridade (usuários/demais conselheiros), rotatividade de representantes de entidades e as constantes "reformulações" da composição do conselho, realizadas, muitas vezes, de maneira informal e sem a devida alteração da legislação pertinente ${ }^{(42,43,44)}$. Sugere-se, desta forma, a capacitação dos 
conselheiros de maneira continuada, com a valorização da realidade local e o incentivo à coesão e à mobilização das entidades de representação popular, com o intuito de modificar esta realidade.

\section{CONCLUSÃO}

No intuito de investigar o conhecimento produzido sobre participação popular, controle social e organização em conselhos gestores de saúde, presentes nas bases de dados, por meio desta revisão integrativa, procurou-se compreender o que está sendo produzido de conhecimento a fim de suscitar novos questionamentos e contribuir para a redução dos hiatos que ainda permeiam o entendimento sobre a participação popular em saúde e os conselhos gestores. Um dos motivos da inércia da população nos últimos 20 anos, no que tange à participação popular, se deve ao grande desenvolvimento da globalização e as mudanças no perfil econômico e social da população, em que se fortaleceu o individualismo em detrimento do coletivo.

Da análise dos artigos para esta revisão, resultou uma compilação de informações relativas à caracterização das atividades e estruturação dos conselhos gestores: a incipiência da participação popular, ainda frágil e pouco resolutiva, sua importância enquanto mecanismo de controle social e a constituição dos conselhos como espaços administrativos com orientações próprias e bem definidas, alicerçados em legislação e com necessidade premente de entendimento dos limites para atuação dos sujeitos envolvidos. Apesar das fragilidades apontadas, é possível afirmar que os conselhos se constituem verdadeiramente em espaços de construção da cidadania e fortalecimento da democracia.

A participação popular perpassa necessariamente pela compreensão e exercício genuíno da cidadania. Para tanto, a realização de capacitação contínua dos conselheiros pode ser uma forma de estimula-los a par- ticipar mais ativamente e emponderá-los para o melhor exercício do seu papel dentro dos conselhos. Os profissionais das Unidades de Saúde da Família também devem ser capacitados no sentido de compreender o verdadeiro papel de um Conselho e a importância de seus atores, para que possam colaborar com o fortalecimento dos Conselhos Locais de Saúde, pois é através da base estrutural da participação popular, iniciada na comunidade adstrita de cada indivíduo, que fortaleceremos o coletivo.

É importante ressaltar que, após análise destes estudos, são passíveis de identificação diversas lacunas de conhecimento referente à temática: não foram encontrados estudos que analisem os modelos de participação popular existente em outros países, por exemplo. Suscitando assim a possibilidade da realização de estudos que analisem de que forma ocorre a participação popular em outros países, e até mesmo de que forma estas experiências podem contribuir em nosso país.

\section{REFERÊNCIAS}

1. Almeida C, Tatagiba L. Os conselhos gestores sob o crivo da política: balanços e perspectivas. Serv. soc. soc. 2012;109:6892.

2. Rolim LB, Cruz RSBLC, Sampaio KJAJ. Participação popular e o controle social como diretriz do SUS: uma revisão narrativa. Saúde debate. 2013;37(96):139-47.

3. Brasil. Lei $n^{\circ} 8.080$ de 19 de setembro de 1990. Dispõe sobre as condições para a promoção e proteção da saúde, a organização e o funcionamento dos serviços correspondentes e dá outras providências. Diário Oficial da União 1990a; 19 set.

4. Brasil. Lei $n^{\circ} 8.142$ de 28 de dezembro de 1990. Dispõe sobre a participação da comunidade na gestão do Sistema Único de Saúde (SUS) e sobre as transferências intergovernamentais de recursos financeiros na área da saúde e dá outras providências. Diário Oficial da União 1990b; 28 dez.

5. Moreira MR, Escorel S. Conselhos Municipais de Saúde do Brasil: um debate sobre a democratização da política de saúde nos vinte anos do SUS. Ciênc. saúde coletiva. 2009;14(3):795-806.

6. Moreira IA, Heidrich AV. Participação social na saúde: limites e possibilidades de controle social em tempo de reforma do Estado. Sociedade em Debate. 2012;18(2):107-119.

7. Kleba ME, Wendhausen A. Empoderamento: processo de fortalecimento dos sujeitos nos espaços de participação social e democratização política. Saúde Soc. 2009;18(4):733-743.
8. Demo P. Participação é Conquista: noções de política social participativa. 3.ed. São Paulo: Cortez; 1996.

9. Gohn MG. Movimentos sociais na contemporaneidade. Rev. bras. educ. 2011;16(47):333-361.

10. Ramos MF, Cezare JP, Vendramini PRJ, Coutinho SMV, Reis TS, Fernandes V. Conselhos setoriais: perfil dos conselheiros e sua influência na tomada de decisão. Saúde Soc. 2012;21(3):6170.

11. Amorim CR, Rocha SV, Nascimento MAA, Cardoso JP, Ribeiro FB, Carneiro LRV. Participação e mobilização social no sus: entraves, desafios e perspectivas. Rev. APS. 2012;15(3):294-298.

12. Souza MT, Silva MD, Carvalho R. Revisão integrativa: o que é e como fazer. Einstein (São Paulo). 2010;8(1):102-106.

13. Ganong LH. Integrative reviews of nursing research. Res. nurs. Health. v.10, n.1, p.1-11, fev.1987.

14. Mendes KDS, Silveira RCCP, Galvão CM. Revisão integrativa: método de pesquisa para incorporação de evidências na saúde e na enfermagem. Texto \& contexto enferm. [periódico na Internet]. 2008 Out-Dez [acessado 2010 Jun 17];17(4): [cerca de 7p.]. Disponivel em: http://bases.bireme.br/cgi-bin/wxislind. exe/iah/online/?IsisScript=iah/iah.xis\&src=google\&base=LILACS\&lang=p\&nextAction=Ink\&exprSearch=507765\&indexSearch=ID

15. Matuoka RI, Ogata MN. Análise qualitativa dos conselhos 


\section{REFERÊNCIAS}

locais da atenção básica de São Carlos: a dinâmica de funcionamento e participação. Rev. APS. 2010;13(4):396-405.

16. Morgan BS, Martins BJ, Fernandes LI, Pereira MS, Bastos MAR. Conselhos de saúde: perfil dos usuários e das entidades por eles representadas. REME rev. min. enferm. 2010;14(3):417423.

17. Ribeiro FB, Nascimento MAA. Exercício de cidadania nos conselhos locais de saúde: a (re) significação do "ser sujeito". Rev. baiana saúde pública. 2011;35(Supl.1):151-166.

18. Silva ERA, Drehmer TM, Langlois CO. Percepção de líderes de uma comunidade de Porto Alegre/RS em relação ao Programa Saúde da Família. Stomatos. 2010;16(30):40-57.

19. Vieira M, Calvo MCM. Avaliação das condições de atuação de Conselhos Municipais de Saúde no Estado de Santa Catarina, Brasil. Cad. saúde pública. 2011;27(12):2315-2326.

20. Santos FAZ, Souza IMC, Gurgel IGD, Bezerra AFB, Barros NF. Política de práticas integrativas em Recife: análise da participação dos atores. Rev. saúde pública. 2011;45(6):1154-1159.

21. Bezerra CKF, Araújo MAD. Conselho Municipal de Saúde de Pedras do Fogo - PB: um estudo sobre participação. Rev. adm. saúde. 2009;11(42):30-42.

22. Zambon VD, Ogata MN. Configurações dos Conselhos Municipais de Saúde de uma região no Estado de São Paulo. Rev. Esc. Enferm. USP. 2011;45(4):890-897.

23. Cotta RMM, Martins PC, Batista RS, Franceschinni SCC, Priore $\mathrm{SE}$, Mendes FF. O controle social em cena: refletindo sobre a participação popular no contexto dos Conselhos de Saúde. Physis (Rio J.). 2011;21(3):1121-1137.

24. Cotta RMM, Cazal MM, Rodrigues JFC. Participação, Controle Social e Exercício da Cidadania: a (des) informação como obstáculo à atuação dos conselheiros de saúde. Physis (Rio J.). 2009;19(2):419-438.

25. Martins PC, Cotta RMM, Mendes FF, Franceschinni SCC, Priore SE, Dias G, Siqueira-Batista R. Conselhos de saúde e a participação social no Brasil: matizes da utopia. Physis (Rio J.). 2009;18(1):105-121.

26. Bispo Júnior JP, Sampaio JJC. Participação social em saúde em áreas rurais do Nordeste do Brasil. Rev. panam. salud pública. 2008;23(6):403-409.

27. Kleba ME, Comerlatto D, Colliselli L. Promoção do empoderamento com conselhos gestores de um pólo de educação permanente em saúde. Texto \& contexto enferm. 2007;16(2):335-342.

28. Budó MLD, Oliveira SG, Garcia RP, Simon BS, Schimith MD, Mattioni FC. Redes sociais e participação em uma comunidade referenciada a uma Unidade de Saúde da Família. Rev. gaúch. enferm. 2010;31(4):753-760.

29. Batagello R, Benevides L, Portillo JAC. Conselhos de saúde: controle social e moralidade. Saúde Soc. 2011;20(3):625-634.

30. Landerdhal MC, Unfer B, Braun K, Skupien JA. Resoluções do Conselho de Saúde: instrumento de controle social ou documen- to burocrático? Ciênc. saúde coletiva. 2010;15(5):2431-2436.

31. Arantes CIS, Mesquita CC, Machado MLT, Ogata MN. Controle social na saúde: discutindo os resultados de uma pesquisa com enfermeiras. Acta paul. enferm. 2009;22(4):417-421.

32. Azevedo DM, Lucena LA, Holanda CSM. O controle social enquanto instrumento para a qualidade da assistência na estratégia de saúde da família. Rev. pesqui. cuid. fundam. (Online) [periódico na internet]. 2012 Out-Dez [acessado $2013 \mathrm{abr}$ 25];4(4): [cerca de 13 p.]. Disponivel em: http://seer.unirio.br/index.php/cuidadofundamental/article/view/2011/pdf_637

33. Kleba ME, Matielo A, Comerlatto D, Renk E, Colliselli L. O papel dos conselhos gestores de políticas públicas: um debate a partir das práticas em Conselhos Municipais de Chapecó (SC). Ciênc. saúde coletiva. 2010;15(3):793-802.

34. Oliveira AGB, Conciani ME. Participação social e reforma psiquiátrica: um estudo de caso. Ciênc. saúde coletiva. 2009;14(1):319-331.

35. Pestana CLS, Vargas LA, Cunha FTS. Contradições surgidas no Conselho Gestor da Unidade Básica de Saúde da Família de Vargem Grande, Município de Teresópolis-RJ. Physis (Rio J.). 2007;17(3):485-499.

36. Machado JM, Farah BF, Barros LM, Assis LTM, Valle NPO, Faria RN. Interação universidade e comunidade através dos movimentos sociais dos bairros Santa Luzia e Ipiranga de Juiz de Fora-MG. Rev. APS. 2009;12(4):398-408.

37. Arantes CIS, Mesquita CC, Machado MLT, Ogata MN. O controle social no Sistema Único de Saúde: concepções e ações de enfermeiras da atenção básica. Texto \& contexto enferm. 2007; 16(3):470-478.

38. Miranda JMB, Guimarães SJ. Controle social e conselhos locais de saúde em teresina: limites e possibilidades. Revista FSA. 2013;10(3):212-227.

39. Diegues GC. O controle social e participação nas políticas públicas: o caso dos conselhos gestores municipais. Revista NAU Social. 2013;4(6):82-93.

40. Teixeira EC. Sistematização: efetividade e eficácia dos conselhos. In: Carvalho MCAA, Teixeira ACC, organizadores. Conselhos Gestores de Políticas Públicas. São Paulo: Pólis; 2000.

41. Cavalcante RB, Silva PC, Ferreira MN. Sistemas de informação em saúde: possibilidades e desafios. Rev. enferm. UFSM. 2011;1(2):290-299.

42. Bispo Júnior JP, Martins PC. Envolvimento comunitário na estratégia de saúde da família: dilemas entre institucionalização e efetiva participação. Physis (Rio J.). 2012;22(4):1313-1332.

43. Zambon VD, Ogata MN. Controle social do Sistema Único de Saúde: o que pensam os conselheiros municipais de saúde. Rev. bras. enferm. 2013;66(6):921-7.

44. Cardoso LS, Cezar-Vaz MR, Costa VZ, Bonow CA, Almeida MCV. Promoção da saúde e participação comunitária em grupos locais organizados. Rev. bras. enferm. 66(6): 928-34. 